\title{
COGNITIVE AHP-MULTIACTOR DECISION MAKING
}

\author{
José María Moreno-Jiménez ${ }^{\mathrm{a}}$, Luis G. Vargas ${ }^{\mathrm{b}}$ \\ a Universidad de Zaragoza, España. Grupo Decisión Multicriterio Zaragoza. \\ Facultad de Economía y Empresa. E-mail: moreno@unizar.es \\ ${ }^{b}$ University of Pittsburgh, USA. Business Operations and Analytics. The Joseph M. \\ Katz Graduate School of Business. E-mail: lgvargas@ pitt.edu
}

\begin{abstract}
This paper presents a methodology, based on the cognitive orientation proposed by the authors in the framework of multiple criteria decision making (Moreno-Jiménez \& Vargas, 2018), but specialized to one of the strong dimensions of the Analytic Hierarchy Process (AHP), multiactor/group decision making. The methodology has two phases. Phase 1 in which decision making takes places with the individual decision makers' judgments, and Phase 2 in which the arguments supporting the individual judgments and positions are identified. The objective is the dissemination of the knowledge derived from the scientific resolution of the problem in order to reach a social learning.
\end{abstract}

Keywords: Cognitive decision making, AHP, Group decision making, Learning

\section{Introduction}

Philosophical, methodological and technological changes have allowed for the transformation of the Information Society into the Knowledge Society. The former transforms information into resources while the latter creates and disseminates raw data. Production and use of data on a global scale does not result in knowledge creation. For that to take place, reflection is required to create awareness, meaning and understanding. For the knowledge Society to be successful it must consider (a) The interdependence of the actors and the factors involved, (b) the collaboration of the actors in the resolution of problems, and (c) the importance of the human factor and hence the need to consider subjective, intangibles and emotional factors in the traditional scientific method. Thus, the new scientific method must consider the continuous education of the individual actors to create a collective intelligence leading to awareness, meaning and understanding.

In this paper we present a cognitive methodology to make decisions with multiple actors in the context of the Analytic Hierarchy Process (AHP). This new way of thinking based on the AHP methodology proposed by Thomas L. Saaty $(1980,1986,1994)$ is characterized by (a) the use of intuition, (b) the ability to work with multiple actors, (c) the integration of the rational and the emotional, and (d) the wholistic view of reality taking into account the interactions among actors and the interdependence of the factors involved.

\section{Background}


Paradigms of rationality represent a scientific approach to decision making. The three most commonly employed paradigms are (Moreno Jiménez et al., 1999; Moreno-Jiménez \& Vargas, 2018): substantive rationality (rational decision maker), bounded rationality (satisficing decision maker) and procedural rationality (descriptive decision maker).

Substantive rationality dominated the field of decision making from the time of its appearance in the middle of the $20^{\text {th }}$ century (Savage, 1954). It is a strict approach characterised by its optimization behaviour (maximum well-being). It is product-oriented (output or decision) and based on having knowledge of the alternatives, their consequences and the criteria followed by the evaluation and comparison of those alternatives. It is a normative approach guided towards prediction and control that explains how the decisions should be made.

Bounded rationality emerged at the end of the 1960s (Simon, 1972) as a response to the cognitive limitations of human beings, e.g., ignorance, stupidity and passion (Kaufman, 1999). It is based on two concepts: 'search' and 'satisficing'. The former is associated with the lack of knowledge of the alternatives whiles the latter refers to achieving goals set by the objectives.

Procedural rationality materialised in the 1970's via the behavioral and sociological approaches to economic decision making (Kanheman and Tversky, 1979). It is oriented towards the process, and it is practical, realistic and formative. Its aim is twofold: understanding and consensus (Moreno Jiménez et al., 1999). Decision making models based on procedural rationality consider intangible and subjective aspects that condition the decisions of individuals and organizations.

The two most common schools of thought regarding decision making are: (i) normative (based on substantive rationality), a strict approximation oriented to the product that indicates how decisions should be taken and the methods that should be used; and (ii) descriptive (based on procedural rationality), a 'soft' approximation oriented to the process that indicates how decisions are taken. At the end of the 1980s (Tversky, 1988), the prescriptive school advanced a 'constructivist' approximation, oriented towards the knowledge that indicates how to improve decision making processes. The prescriptive school utilises new paradigms of rationality such as Soft Systems, Post-normal Science, Postmodernism, Critical Realism, and Multicriteria Procedural Rationality, among others.

In this framework, the new scientific method must have a cognitive orientation. It must be aimed at the continuous education of individuals (and the systems in which they are immersed) in that distinctive aspect of human beings - the ability to make decisions ('scientifically', in this case). The new methodology must add a further stage to the stages that are traditionally included in the scientific resolution of problems: cognition, both individual and societal. It is not enough to reach the optimum decision or solution (the product) or increase the knowledge and rigour of the resolution process; there must be an orientation towards improving the knowledge of people.

\section{The Cognitive Orientation in the Analytic Hierarchy Process}

This requires the systematization of the cognitive exploitation of decisional processes (Moreno-Jiménez et al., 2014). There are four main stages: i) the detailed Formulation of the problem, specifying all the relevant elements from a cognitive point of view; ii) the Discussion by the actors involved in the resolution of the problem (a discussion stage 
between two voting rounds in which the preferences of decision makers are incorporated); iii) the Exploitation of the mathematical model to extract the maximum knowledge possible (patterns, critical points, decision opportunities, arguments that support positions etc.); and, iv) the Diffusion (including Visualisation) of knowledge. In addition, as a starting point for learning and continuing education, a fifth stage, Accountability, is advisable. This is an evaluation of the efficiency (doing things correctly), the efficacy (achieving goals) and, in particular, the effectiveness (doing what is right in order to resolve the problem) of the resolution process.

The Discussion stage contemplated in the cognitive orientation requires that a systematic procedure must be established that allows us to: (i) take advantage of the talent and experience of actors; (ii) link the arguments with the preferences; (iii) incorporate quantitative information and qualitative knowledge; (iv) measure the individual importance and social relevance of the themes (messages and comments) as well as the individual confidence and social reputation of the participating actors; (v) evaluate the degree of compatibility between the individual and collective positions; (vi) determine the discrepancy thresholds which can be the basis for a new order in situations that are distant from the equilibrium (social dissipative structures); (vii) incorporate social networks into the electronic participation (e-participation) processes, and, (viii) guarantee the levels of security demanded by e-discussion and e-decision procedures.

The Exploitation of the mathematical model (in our case, AHP) and the information and knowledge generated in the Discussion stage allow us to: (a) measure the changes in collective and individual preferences; (b) extract the arguments that support the opinions and decisions; (c) identify the social leaders and most significant themes; and, most importantly, (d) measure the value added by the increase in individual and collective knowledge produced by the technique that is employed.

\section{Group Decision Making and the Legacy of AHP}

One of the most difficult tasks that modelers face is the incorporation of human behavior into decision making. It is known that human behaviour is not always rational in the way it is assumed by the rational choice school. In recent years a new way of thinking has evolved using psychology and economics that is trying to show that transitivity need not always be satisfied to be a rational decision maker.

Kahneman and Tversky (1979) showed the many problems that expected utility theory has as a descriptive theory of behavior leading to preference reversals; and Tversky and Thaler (1990) provided some plausible explanations as to how preference reversals may occur when people make decisions. Richard Thaler, the 2017 Nobel Prize in Economics, has demonstrated that mankind is afflicted by emotion and irrationality, which influences their decision making on everything from retirement savings, to health-care policy, to professional sports. This is in complete agreement with what Thomas L. Saaty has been saying for years.

Saaty's theory $(1977,1980,1986)$ the Analytic Hierarchy Process (AHP), is based on the idea that making decisions need not assume transitivity. One could go one step further and imply that the lack of transitivity in preferences may lead to rank reversals. It is one of the reasons why Saaty's theory has been criticized. However, a theory of decision making should allow for intransitivity if we expect to capture what Thaler (2017) calls "predictably irrational" behavior. Thaler does not believe that human beings are 
randomly irrational. He is not the only one who believes this to be the case. Ariely (2008) also challenges the assumptions about making decisions based on rational thought.

We believe we make decisions by comparing alternatives in pairs according to different criteria, but for every pairwise comparison, we only have one and only one criterion in mind. We perform all the comparisons according to all the criteria, and somehow, we synthesize all the comparisons in our brain to arrive at the final decision. Saaty created his theory to help model this process and incorporate the experience, talent and knowledge of the actors involved in the resolution process.

However, as a theory of decision making, the AHP, and its extension to networks the Analytic Network Process (ANP), approximates how we actually make decisions.

AHP provides the flexibility of accepting or rejecting transitivity in the modelling process. We know that a necessary and sufficient condition for rank preservation in the AHP is row dominance (Saaty and Vargas, 2012). Nonetheless, people are not always transitive, and hence, they violate a fundamental premise of the rational choice school and, Thaler's "predictably irrational" behaviour follows.

When Saaty conceived AHP, he envisioned three fundamental problems that needed to be addressed:

\section{(1) Group decision making}

Now more than ever, group decision making is critical at all societal levels. Problems are becoming more complex requiring multiple experts to understand all dimensions of problems, and the implications of decisions are multidimensional. We need to be able to make decisions in groups without the fear of having a decision being imposed on us. This would be the case, if all we do is ranking alternatives, because then we could fall under the umbrella of Arrow's Impossibility theorem. We need to ensure that a decision by a group is not a dictatorial one. Saaty and Vargas (2012) showed that it is possible to make decisions in groups without being dictatorial if intensity of preference given by the individual judgments is represented with an absolute scale, and the social welfare function is a ratio scale derived from the geometric mean of the individual judgments.

(2) Conflict resolution

In 1981 the book "Getting to YES" (Fisher and Ury, 1981) revolutionized the way conflicts were looked at. Fisher and Ury introduced the concept of principled negotiation in which participants are problem solvers. The approach is based on four principles: (i) Separate the people from the problem; (ii) Focus on interests not positions; (iii) Invent options for mutual gain, and (iv) Insist on using objective criteria. In this approach, parties do not see each other as adversaries but rather as collaborators in search of a fair solution.

However, the approach does not measure gains and losses of parties for different options. Thus, the parties may not be able to perceive how fair a proposed solution is. What is needed is the development of scales that represent the preferences of the parties. It is not enough to assign numbers to preferences without any mathematical assumptions because we want to ensure that the results belong to a measurement scale.

This is a difficult problem if the dimensions of the conflict involve intangibles, which by definition are considered not to have a scale of measurement. Pairwise comparisons from Saaty's absolute scale (Saaty, 1977) can be used to build such relative measurement scales. In Saaty et al. (2017), this approach was used to show that a fair solution (in the eyes of those involved in the process) could be developed. 
This is just one of many examples that show that to deal with conflicts, the negotiation approach needs to be measurement based. Since intangibles are always involved, we need pairwise comparisons to build measurement scales, that are then used to compute gain/loss ratios of tradeoffs from each party's perspective. Gain/loss ratios are not symmetric and the tradeoffs are non-zero sum. Hence, measurement allows for the selection of tradeoffs for which both parties benefit equally through a MaxMin optimization model.

(3) Pairwise comparisons and neural activity

The nervous system uses its own kind of mathematical function patterns to deal with both external and internal realities. The conscious part of the nervous system is there to respond to what happens outside by regulating externally received information signals from the senses and the skin and muscles of the body itself. To do that, it needs to communicate with its subconscious using the familiar language of neural firing. Saaty and Vargas (2017) show that because reciprocal pairwise comparisons are performed at the neural level, the division algebra of octonions (Baez, 2001), in which commutativity and associativity are not satisfied, provides a structure to represent mental processes.

Saaty showed, while extending the discrete pairwise comparisons to continuous spaces, that the response of a neuron in spontaneous activity, $w(s)$, is an eigenfunction solution of a Fredholm's integral equation of the second kind if and only if it satisfies the functional equation $\mathbf{w}(a s)=b \mathbf{w}(s)$, where s represents stimuli (Saaty, 2015; 2017a,b). Saaty called this equation the fundamental equation of pairwise comparisons. Its solution in the space of octonions is given by $\tilde{w}(u)=a^{\left(\frac{\ln b}{\ln a}\right) u} P(u) \oplus P(u) a^{\left(\frac{\ln b}{\ln a}\right) u}$, where $P(u)$ is a periodic function of period 1. It satisfies the condition $\tilde{w}(u v)=\tilde{w}(u) \tilde{w}(v)$ if $P(u)$ satisfies the semigroup condition $P(u+v)=P(u) P(v)$, and it can generate the group of automorphisms, G2.

In $\mathrm{G}_{2}$, these functions are given by $\tilde{w}(u)=b^{u} e^{2 n \pi u}$, and they are dense in the space of continuous functions defined on the octonions. Thus, all continuous functions could be expressed as linear combinations of the solution of the equation, and they could generate the group of automorphisms. In sum, any representation of brain activity with octonions could be expressed with the solution of the equation $\mathbf{w}(a s)=b \mathbf{w}(s)$. According to this result, the firing of neurons through the continuous paired comparison process generates a smooth $\mathrm{G}_{2}$-manifold in which cognition and the representations of our thoughts could take place (Saaty and Vargas, 2017).

\section{Conclusions}

This work applies the cognitive orientation proposed by the authors (Moreno-Jiménez \& Vargas, 2018) in multicriteria decision making environments to one of the most relevant features of the AHP, group decision making. This cognitive orientation based on the evolution of living system seeks the creation of collective knowledge to continuously educate individuals in a vital dimension of human beings, (scientific) decision making.

To accomplish this, the proposed methodology includes a new phase (cognition) in the resolution process. Cognition identifies and shares the arguments supporting different positions and decisions. Arguments are extracted, using text mining techniques, from the messages and comments incorporated during the discussion phase. This phase takes place between the two voting rounds included in the methodology, Linking preferences 
ISAHP Article: A Style Guide for Paper Proposals To Be Submitted to the International Symposium on the Analytic Hierarchy Process 2018, Hong Kong, HK.

and arguments allows for the identification of the most relevant actors (e.g., social leaders) and the measurement of individual and collective learning. Likewise, the actors' reputations and the importance of the considered topics are updated.

Future activities could include the incorporation of the value added of knowledge obtained in the application of the cognitive orientation to multicriteria decision making problems. The measurement of this knowledge value added would allow us to compare the effectiveness in knowledge creation of different schools of thought in multicriteria decision making.

\section{References}

Ariely, D. (2008). Predictably Irrational: The Hidden Forces That Shape Our Decisions. Harper Collins Publishers.

Baez, J.C. (2001). The Octonions. Bulletin of the American Mathematical Society 39(2), 145-205.

Fisher, R., URY, W. (1981). Getting to YES: Negotiating Agreement Without Giving. New York, Penguin Books.

Kaufman, B.E. (1999). Emotional arousal as a source of bounded rationality. Journal of Economics Behaviour \& Organization 38, 135-144.

Kahneman, D., Tversky, A. (1979). Prospect Theory: An Analysis of Decision Under Risk. Econometrica 47(2), 263-291.

Moreno-Jiménez, J.M., Aguarón, J., Escobar, M.T. Turón, A. (1999). Multicriteria Procedural Rationality on SISDEMA. European Journal of Operational Research 119(2), 388-403.

Moreno-Jiménez, J.M., Cardeñosa, J., Gallardo, C., de la Villa-Moreno, M.A. (2014). A new e-learning tool for cognitive democracies in the Knowledge Society. Computers in Human Behavior 30, 9-18.

Moreno-Jiménez, J.M., Vargas, L.G. (2018). Cognitive Multicriteria Decision Making and the Legacy of the Analytic Hierarchy Process. Estudios de Economía Aplicada 36(1), 67-79.

Saaty, T.L. (1977). A scaling method for priorities in hierarchical structures. Journal of Mathematical Psychology 15, 234-281.

Saaty, T.L. (1980). The Analytic Hierarchy Process. McGraw Hill, New York.

Saaty, T.L. (1986). Axiomatic foundation of the analytic hierarchy process. Management Science 32(7), 841-855.

Saaty, T.L. (1994). Fundamentals of Decision Making. RSW Publications. Pittsburgh.

Saaty, T.L. (2015). The Neural Network Process (NNP): Generalization of the AHP and ANP to the Continuous Case of Neural Firing. RWS Publications (www.rwspublications.com).

Saaty, T.L. (2017a). Neurons the decision makers, Part I: The firing function of a single neuron. Neural Networks 86, 102-114.

Saaty, T.L. (2017b). Neurons the decision makers, Part II: The firings of many neurons and their density; the neural network its connections and field of firings. Neural Networks $86,115-122$. 
ISAHP Article: A Style Guide for Paper Proposals To Be Submitted to the International Symposium on the Analytic Hierarchy Process 2018, Hong Kong, HK.

Saaty, T.L., Vargas, L.G. (2012). The Possibility of Group Choice: Pairwise Comparisons and Merging Functions, Social Choice and Welfare 38(3), 481-496.

Saaty, T.L. and Vargas, L.G. (2017). "Origin of Neural Firing and Synthesis in Making Comparisons". European Journal of Pure and Applied Mathematics 10(4), 602-613.

Saaty, T.L., Vargas, L.G., Zoffer, H.J. (2017). A structured scientific solution to the Israeli-Palestinian conflict: the Analytic Hierarch Process approach. Decision Analytics 2(7), 2-53.

Savage, L.J. (1954). The Foundations of Statistics. John Wiley and Sons. New York.

Simon, H.A. (1972). Theories of bounded rationality. In C. B. Radner y R. Radner (eds.):

Decision and Organization. North Holland Publishing Company. Amsterdam.

Thaler, R.H. (2017). Misbehaving: The Making of Behavioral Economics. W.W. Norton - via Google Books.

Tversky, A. (1988). A rational choice and the framing of decisions. In D.E. Bell; H. Raiffa, \& A. Tversky (Eds.), Decision making: Descriptive, normative, and prescriptive interactions. Cambridge University Press.

Tversky, A., Thaler, R.H. (1990). Anomalies: Preference Reversals, The Journal of Economic Perspectives 4(2), 201-211. 